\title{
The impact of efficient insulation on thermal performance of building elements in hot arid region
}

\author{
Ghanim Kadhem Abdulsada ${ }^{1}$ and Tawfeeq Wasmi Mohammed Salih ${ }^{2,}$ (D) \\ ${ }^{1}$ Mechanical Engineering Department, Dijlah University, Iraq \\ 2 Materials Engineering Department, Mustansiriyah University, Iraq
}

Received: 16 July 2021 / Received in final form: 2 November 2021 / Accepted: 2 November 2021

\begin{abstract}
The application of thermal insulation technique for buildings in hot arid region still under development and requires investigation for many aspects, especially those related to the individual elements of the construction. The present study investigates the impact of efficient insulation on the thermal performance of the following construction elements: wall, roof and foundation. The techniques used for the insulation have followed the Passive House criteria. The study introduces many benefits for passive design of the building in extreme hot climate. The work has done experimentally in Kirkuk, Iraq for two building models; one is efficiently insulated and the other is traditional. The data, which are collected in summer time, show reduction in indoor temperature of the efficient model by $8^{\circ} \mathrm{C}$ in average comparing to that of traditional one. Measurements show stability in the internal wall temperatures for efficient model with an average temperature of $33^{\circ} \mathrm{C}$ comparing to $42^{\circ} \mathrm{C}$ for traditional one. Similarly, the insulated roof radiates less heat into the indoor than that of traditional model. Furthermore, the effect of both efficient insulated roof and canopy shading reduces the temperature of internal surface temperature of the roof by $12{ }^{\circ} \mathrm{C}$ comparing to the traditional model. A local simulation program based on ASHRAE relations has shown an energy saving in the cooling load up to $70 \%$.
\end{abstract}

\section{Introduction}

Air-conditioning in Iraq, where the climate is extremely hot in the summer, consumes more than $60 \%$ of the electrical energy supplied to the residential building [1]. In such climate, the cooling load is exceeded the power capacity, and building elements suffer from undesired conditions lead to thermal stresses, and thus to crack and mold [2]. This issue could be treated by using efficient insulation for external walls and roof. Thermal performance of an insulation system could be evaluated depending on the amount of heat transferred via it. In order to minimize the heat transfer it is required to follow [3]:

- Low thermal conductivity materials to minimize the conduction.

- Evacuated portions to minimize the convection.

- Low emittance and high reflective surfaces to attenuate the radiation.

Several studies have conducted in the development of efficient insulation for buildings in hot arid regions. Most of these studies have looked for innovative insulation techniques and investigated the optimum $U$-value required

\footnotetext{
* e-mail: tawfeeq1978@yahoo.com
}

to ensure efficient insulation of building element. Some researchers have investigated alternative solutions as well. Al-Homoud [4] have introduced an overview regarding the impact of building envelope thermal design on the effectiveness of buildings in different hot climates. He emphasizes the role of proper insulation materials in achieving the desired objectives as a function of building type and climatic conditions. A theoretical study carried out by Almusaed et al. [5] has shown that the improving of energy performance of Iraqi buildings can be achieved using: insulation material, shades and air cooling. The U-value of the optimized wall must be not exceeding $0.12 \mathrm{~W} / \mathrm{m}^{2} \mathrm{~K}$. For an efficient roof it needs to satisfy $U$-value of $0.082 \mathrm{~W} / \mathrm{m}^{2} \mathrm{~K}$ by using $15 \mathrm{~cm}$ of mineral wool. A simulation program to figure out the contribution of insulation materials in hot climate in Spain was presented by ISOVER (2008) [6]. The simulation was carried out using the dynamic thermal building application DYNBIL. Comparisons with several measurements taken in inhabited buildings had shown a very good accordance. Excellent insulation of the roof and walls $\left(U<0.2 \mathrm{~W} / \mathrm{m}^{2} \mathrm{~K}\right)$ reduced the cooling load in summer. Insulation between the building and the ground was not required because the ground temperature was close to $20^{\circ} \mathrm{C}$. Hence, the ground can store excess heat in summer. Common materials used 
for construction in Thailand are brick and mortar with reinforced concrete. These materials are not satisfying energy efficient building in hot climate. Therefore, Pongsuwan [7] suggested that the application of thermal insulation from outside of Thai buildings improves the comfort of occupants and reduces heat transfer approximately 10 times comparing to conventional buildings. Another study in Iraq carried out by Kalif et al. [8] tried to calculate the effect of packaging materials on the cooling load. The study conducted a survey of several materials and it also included testing and thermal analysis. A computer programming has done to estimate the amount of cooling load through the walls by using Cooling Load Temperature Differences (CLTD) method described by ASHRAE [9]. Results show that the percentage reduction in cooling load when using internal packaging materials ranges between $5 \%$ and $12 \%$. An experimental study carried out by Abdulsada and Mohammed [10] proposed a reduction in the energy consumption in Iraqi building by eliminating the effect of direct solar radiation in summer season using sufficient insulation system. The study has taken place in a terrace testing room using a new thermal insulation made of expanded charcoal to cover walls and roof with an air gap of $5 \mathrm{~cm}$. The results revealed that the proposed system can save the annual cooling load for the room by $6 \mathrm{MW}$ and that the indoor temperature may down to $35^{\circ} \mathrm{C}$ for outdoor temperature around $45^{\circ} \mathrm{C}$. In the hot Saharan climate, thermal storage in building elements can play a negative role on the desired comfort conditions. This issue can be eliminated by enhancing the thermal insulation of facades by inserting reflective films as well as serving appropriate ventilation systems, as proposed by Bekkouche et al. [11]. Aboulnaga and Moustafa [12] aimed to modify an existing multi-floor building in Egypt, by suitable insulation materials, using simulation tools. The study determined the baseline assessment of the building energy performance and compared it with its original energy consumption. The overall reduction was about $15 \%$ from the baseline energy consumption. The interest of using bio-composites in the construction has increased recently in order to achieve high thermal resistance, reduce greenhouse gases (GHGs) as well as the recycling of waste materials. A research by Ouakarrouch et al. [13] has studied the developing of plaster in Moroccan construction by mixing it with waste chicken feathers (WCF) in order to be used as external wall covers. The results have shown that the addition of WCF leads to a remarkable reduction in the thermal conductivity by $30 \%$. Selecting the appropriate thickness of insulation is an important factor for energy efficient building. Typical hypothetical building is simulated in China by Liu et al. [14] in the hot summer season. Expanded polystyrene is chosen as insulation layer with thickness ranges between 30 and $150 \mathrm{~mm}$. It is found that the optimal economic insulation thickness for the desired conditions was $70 \mathrm{~mm}$. Alwetaishi et al. [15] introduces alternative suggestion for site construction in hot region which based on the underground building by digging the earth, internal design for the space up to the finishing. The design includes roof insulation as well as windows above the ground as skylights and for the purpose of natural ventilation. The

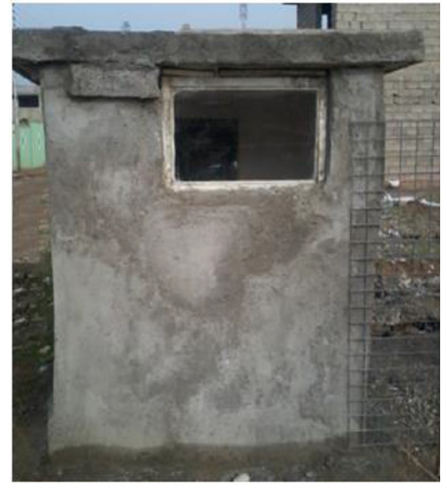

(a)

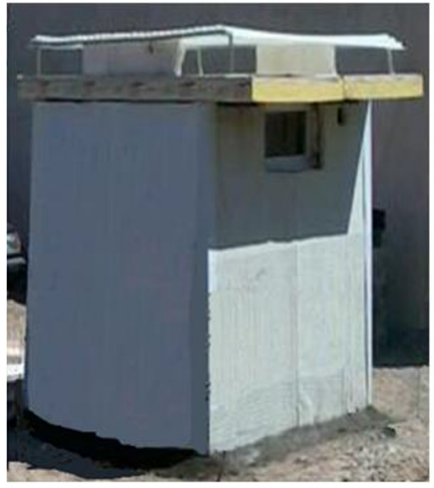

(b)
Fig. 1. Models constructed in the current study. (a) traditional model; (b) efficient model.

study conducted experimentally with field measurements to ascertain the indoor temperature as well as relative humidity. It was revealed that the use of this model can lower the indoor temperature by $3^{\circ} \mathrm{C}$ at least in summer. Some studies $[16,17]$ claimed that the applying of insulation materials to building surfaces increases the air-conditioning load in some cases, where an isolated surface may restrain the dissipation of the internal gain to the exterior ambient and that leads to overheating. However, this issue is limited for certain conditions and may be true for humid climate.

The current study aims to investigate the benefits of using an efficient insulation technique on the thermal performance of building elements, namely: wall, roof and foundation. The technique has followed Passive House design which is globally recommended as energy efficient building criteria [18-20]. The work introduces experimental results for two building models; one is efficiently insulated and the other is traditional. Furthermore, the study introduces many solutions for passive design of the building in extreme hot climate, such as insulated foundation, double glazing, avoiding thermal bridges, air-tightness, underground ventilation system as well as canopy shading.

\section{Procedure of the work}

The aim of this study is to satisfy efficient insulation for Iraqi buildings that can withstand extreme hot weather in the summer. The study has been done experimentally using two models built in Kirkuk mid-north of Iraq $\left(35.5^{\circ} \mathrm{N}\right.$, $44.4^{\circ} \mathrm{E}$ ). The first model has built in a traditional way without any insulation, while the second model has built with efficient insulation standards. The two models have the same dimensions $(1.8 \mathrm{~m} \times 1.8 \mathrm{~m} \times 2 \mathrm{~m})$, Each model has a window of $(0.8 \mathrm{~m} \times 0.5 \mathrm{~m})$ south orientation and a door of $(1.9 \mathrm{~m} \times 0.9 \mathrm{~m})$ north orientation, as shown in Figure 1 . The traditional model has built using a conventional procedure, where the walls are constructed from $20 \mathrm{~cm}$ common hollow block, $2 \mathrm{~cm}$ external cement-plaster and $1 \mathrm{~cm}$ internal gypsum-plaster, while the roof is constructed from $15 \mathrm{~cm}$ reinforced concrete with $1 \mathrm{~cm}$ internal gypsumplaster. 


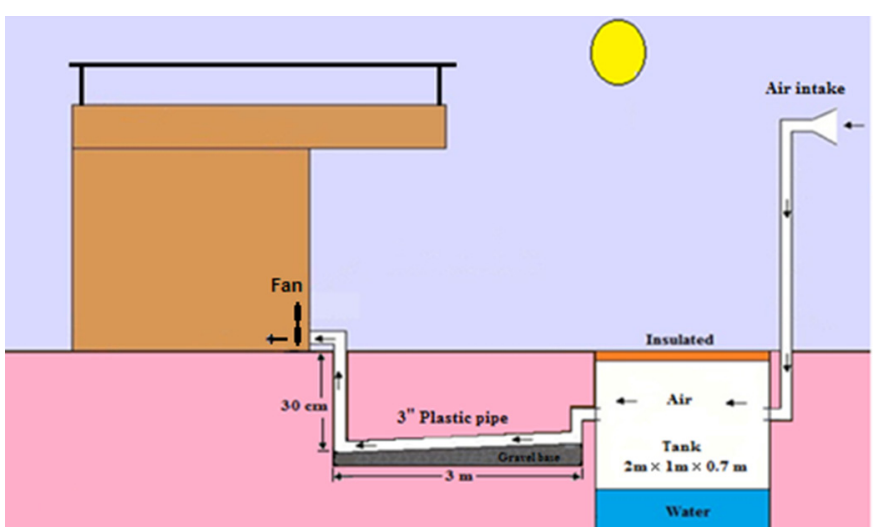

Fig. 2. Scheme of the efficient model.

The efficient model has some innovative techniques. The outer face of the foundation has insulated by $4 \mathrm{~cm}$ cork to prevent heat transfer from the surrounding area to the interior space. Walls have built up to $2 \mathrm{~m}$ high using the standard $15 \mathrm{~cm}$ hollow block, and initially insulated by $2 \mathrm{~cm}$ cork. After that, walls have covered by bubbly wrap of $4 \mathrm{~mm}$ thickness made up from polyethylene as a condensation barrier. Finally, walls have insulated by $10 \mathrm{~cm}$ polyurethane panels and covered by reflected sheets. The overall $U$-value of the walls was $0.15 \mathrm{~W} / \mathrm{m}^{2} \cdot \mathrm{K}$. Roof has installed using standard polyurethane sandwich panel of $15 \mathrm{~cm}$ thickness, so the overall $U$-value for the roof was $0.19 \mathrm{~W} / \mathrm{m}^{2} \cdot \mathrm{K}$. Since, the roof is exposed to high intensity of solar radiation, so it has been covered by a canopy of plastic layer. Double glazing closed-type window of plastic frame was used. The overall $U$-value of the window was $1.1 \mathrm{~W} / \mathrm{m}^{2} \cdot \mathrm{K}$. Door of UPVC frame and double insulated sheetes was used with overall $U$-value of $1.8 \mathrm{~W} / \mathrm{m}^{2} \cdot \mathrm{K}$. Thermal bridges around the walls, roof, window and door have avoided using EPS cork of $2 \mathrm{~cm}$ thickness. The airtightness was checked to decrease any leakage. In order to satisfy energy efficient standards, underground air ventilation system (UAVS) has implemented, as shown in Figure 2. Air has entered to the efficient model through a stream connected to an underground passage and extracted from an external diffuser. The specifications of the system are listed in Table 1.

The study includes in-site measurements on the constructed models within two months (August and September). Several instruments have been used in the work. Lutrun data logger system has been used to measure outdoor temperature, indoor temperature and surfaces temperature for different locations each $15 \mathrm{~min}$ throughout the day. The global solar radiation was measured as well using solar power meter (Lutron-Model SPM-1116SD).

\section{Results and discussions}

Data were collected in summer 2013 (August 06-September 23), where there is high solar radiation and hot ambient temperature. Generally, results show valuable decreasing in the indoor temperature for the case of efficient insulated model compared to that of traditional one, as shown in Figure 3. The average indoor temperature in efficient
Table 1. Specifications of ventilation system implemented in the current study.

\begin{tabular}{ll}
\hline Item & Specifications \\
\hline Air intake and draft & $\begin{array}{l}\text { Plastic of } 8 \text { inches inlet diameter } \\
\text { pipe }\end{array}$ \\
Underground tank & $\begin{array}{l}2 \mathrm{~m} \times 1 \mathrm{~m} \times 0.7 \mathrm{~m} \text { filled } \\
\text { partially by water }(1 / 3) \text { and } \\
\text { well insulated. }\end{array}$ \\
& $\begin{array}{l}\text { Plastic pipe of } 3 \text { inches diameter } \\
\text { connects between underground } \\
\text { Delivery pipe }\end{array}$ \\
& $\begin{array}{l}\text { tank and building entrance. } \\
\text { Located at the building entrance } \\
\text { and has ventilation rate of } 0.4\end{array}$ \\
& ACH. \\
\hline
\end{tabular}

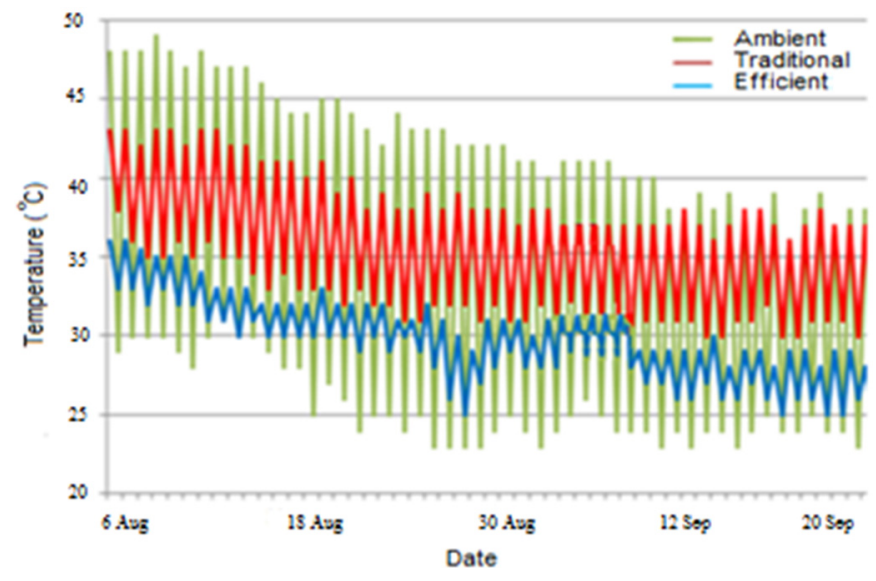

Fig. 3. Variation of indoor and outdoor temperatures during summer 2013.

insulated model was $32{ }^{\circ} \mathrm{C}$ with maximum value of $34^{\circ} \mathrm{C}$. While, in the traditional one, it was $40^{\circ} \mathrm{C}$ with maximum value of $44^{\circ} \mathrm{C}$. Results show clearly that there is a low flactuating in indoor temperature of efficient model, about $4{ }^{\circ} \mathrm{C}$, compared to that of traditional one which is fluctuated by $8^{\circ} \mathrm{C}$. However, maximum indoor temperature has occurred after $3 \mathrm{PM}$ due to high accumulated heat.

\subsection{Thermal performance of the wall}

The internal surface temperature varies with respect to construction materials and orientations. In the present work, the temperature of the internal surfaces in the efficient model was lower than that in the traditional one by $4-8^{\circ} \mathrm{C}$, as shown in Figures 4 and 5 . Efficient insulation keeps the internal surface temperature around $33^{\circ} \mathrm{C}$. On the other hand, the internal temperature of un-insulated wall raises up to $42{ }^{\circ} \mathrm{C}$. Peak temperature has occurred at noon time for the east wall, while it is occurred at evening for other direction walls and the roof. The reason of high temperature rise in the peak times is due to the lack of thermal resistance of the building element in certain extreme conditions. The high fluctuating values affect the strength of construction materials due to thermal stresses, 


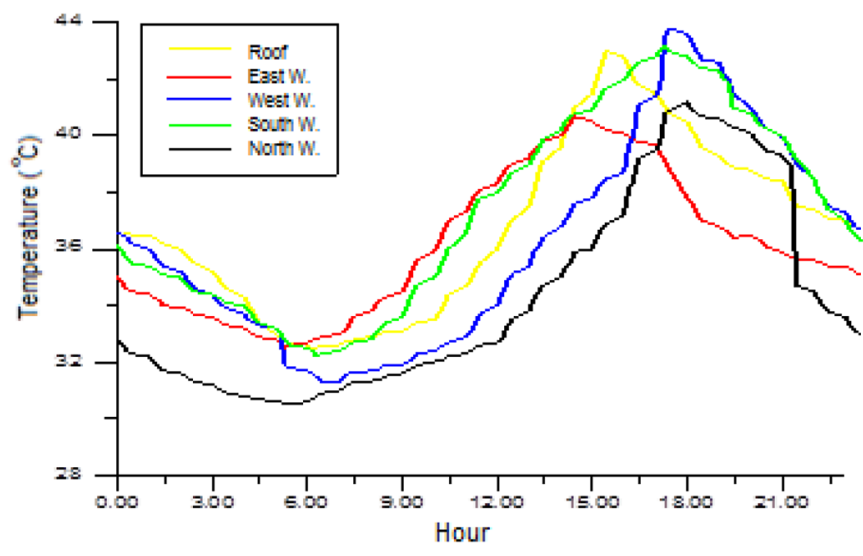

Fig. 4. Internal surface temperature in the traditional model (15-08-2013).

and lead to crack and mold. Results show that heat transmitted through east wall is actually more than that of south wall because the sun has low angle at the morning, so the solar radiation reaches directly to the walls compared with midday period where the radiation lies upon the roof. Furthermore, the heat transmission via west wall is less than that of east wall, because the intensity of the solar radiation at evening is lower than that at the morning due to dust activity afternoon usually. As a rule of thumb, internal surface temperature for efficient insulated building should not differ more than $1^{\circ} \mathrm{C}$ to the indoor air temperature. This fact is also mentioned by ISOVER [6].

\subsection{Thermal performance of the roof}

Obviously, the roof is the most building element exposed to solar radiation. Therefore, it requires more processing besides the insulation to decrease the heat transfer. For example, the roof can be covered by shades of light fabrics or climbing plants. Shading can reduce indoor air temperature as much as $5^{\circ} \mathrm{C}$ [5]. In the present work, the measured values of temperatures in the traditional model show extra rise of roof temperature, where the internal surface temperature was around $44^{\circ} \mathrm{C}$, as shown in Figure 4. So, a plastic layer was used to provide canopy shading to the roof of the efficient model beside the insulation. In general, the temperature of the internal surface of the efficient model with shaded roof has decreased to $32{ }^{\circ} \mathrm{C}$, as shown in Figure 5 . The effect of canopy shading is very valuable. Results show that the average reduction in the temperature of external surface of the roof was $10^{\circ} \mathrm{C}$, as shown in Figure 6a, and the average reduction in the temperature of internal surface of the roof was $3^{\circ} \mathrm{C}$, as shown in Figure $6 \mathrm{~b}$.

\subsection{Thermal performance of the foundation}

In order to recognize the effect of insulation on thermal performance of the foundation, earth temperature, as well as temperature of outer face of the foundation were measured for different depths, as shown in Figure 7. It was found that earth temperature decreases gradually with

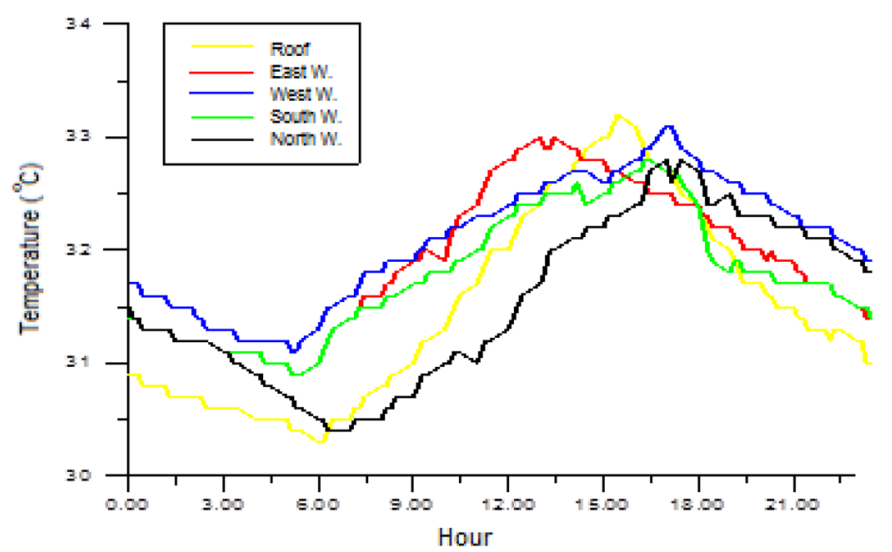

Fig. 5. Internal surface temperature in the efficient model (15-08-2013).

depth far from the datum surface till a depth of $0.4 \mathrm{~m}$ where the temperature difference becomes negligible. Since, the outer face temperature of the foundation is affected by the earth temperature, so it should be insulated for a certain depth to avoid thermal bridge and eliminate the heat transfer from the external surrounding to the inside. Hence, it is recommended to use cork of $4 \mathrm{~cm}$ thickness. Insulation between the floor and the ground is not required because the ground can absorb excess heat in summer.

\subsection{Overall thermal performance of the building}

A local simulation program based on ASHRAE relations [9] has used to calculate the cooling load according to the following equation:

$$
Q=U A\left(T_{o}-T_{i}\right)
$$

where $Q=$ heat transfer in (W); $U=$ overall heat transfer coefficient in $\left(\mathrm{W} / \mathrm{m}^{2} \cdot \mathrm{K}\right) ; A=$ surface area in $\left(\mathrm{m}^{2}\right) ; T_{o}=$ outdoor temperature $(\mathrm{K}) ; T_{i}=$ indoor temperature $(\mathrm{K})$.

Note that the temperature difference is varied with respect to the orientation of the element which a dominant parameter in the Cooling Load Temperature Differences (CLTD) method described by ASHRAE. Take into account the following considerations:

- $U$-value of the wall is $0.15 \mathrm{~W} / \mathrm{m}^{2} \mathrm{~K}$.

- $U$-value of the roof is $0.19 \mathrm{~W} / \mathrm{m}^{2} \mathrm{~K}$.

- $U$-value of the floor is $0.16 \mathrm{~W} / \mathrm{m}^{2} \mathrm{~K}$.

- $U$-value of the window is $1.1 \mathrm{~W} / \mathrm{m}^{2} \mathrm{~K}$.

- $U$-value of the door is $1.8 \mathrm{~W} / \mathrm{m}^{2} \mathrm{~K}$.

The ventilation rate for the proposed system was 0.4 ACH. Furthermore, the coefficient of thermal bridge was less than $0.015 \mathrm{~W} / \mathrm{m}^{2} \mathrm{~K}$, which is required by passive house criteria. Thus, the overall cooling load in absence of the internal heat sources can be calculated by:

$$
\text { Load }=\frac{Q_{\text {walls }}+Q_{\text {roof }}+Q_{\text {floor }}+Q_{\text {window }}+Q_{\text {door }}+Q_{\text {vent. }}}{3500}
$$




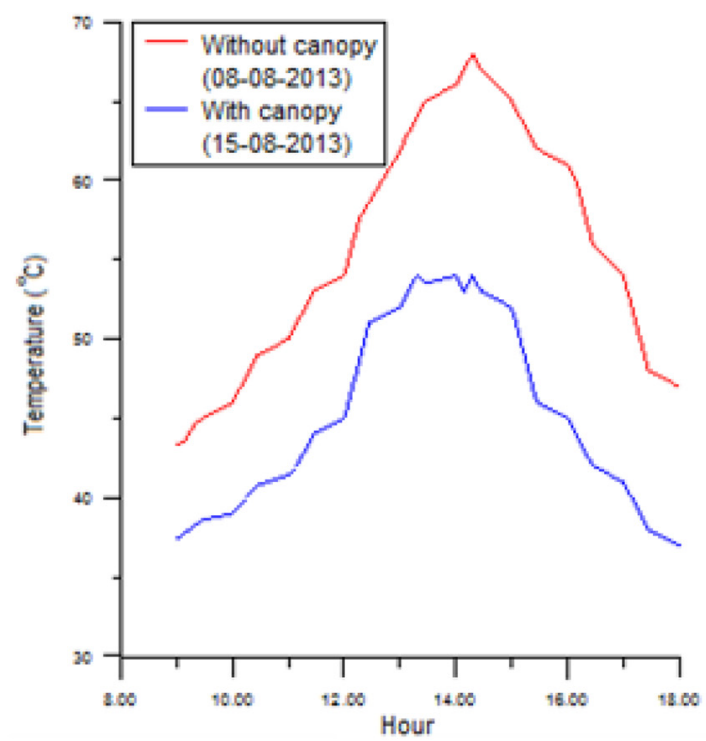

(a)

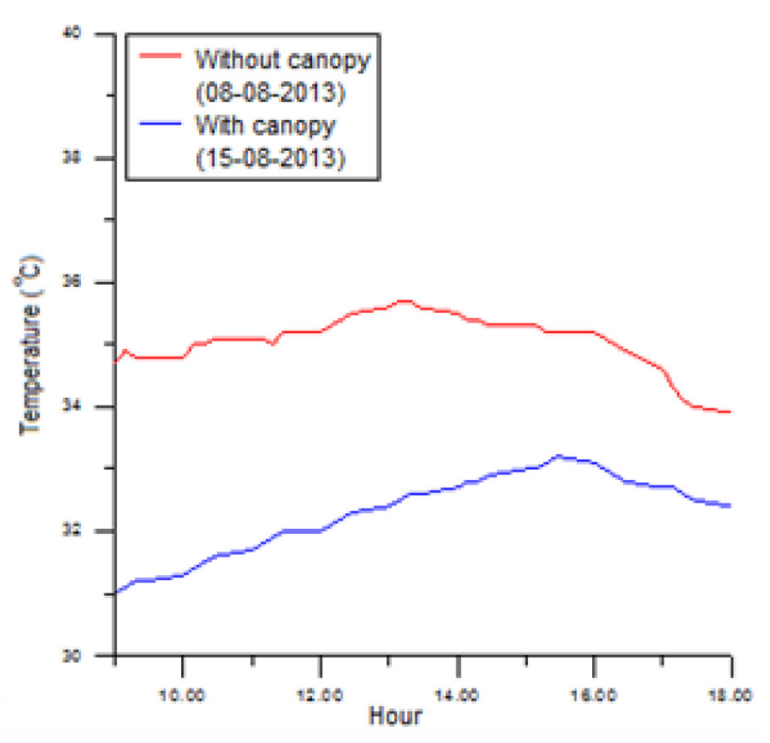

(b)

Fig. 6. Surface temperatures of the roof in the efficient model. (a) external surface temperature; (b) internal surface temperature.

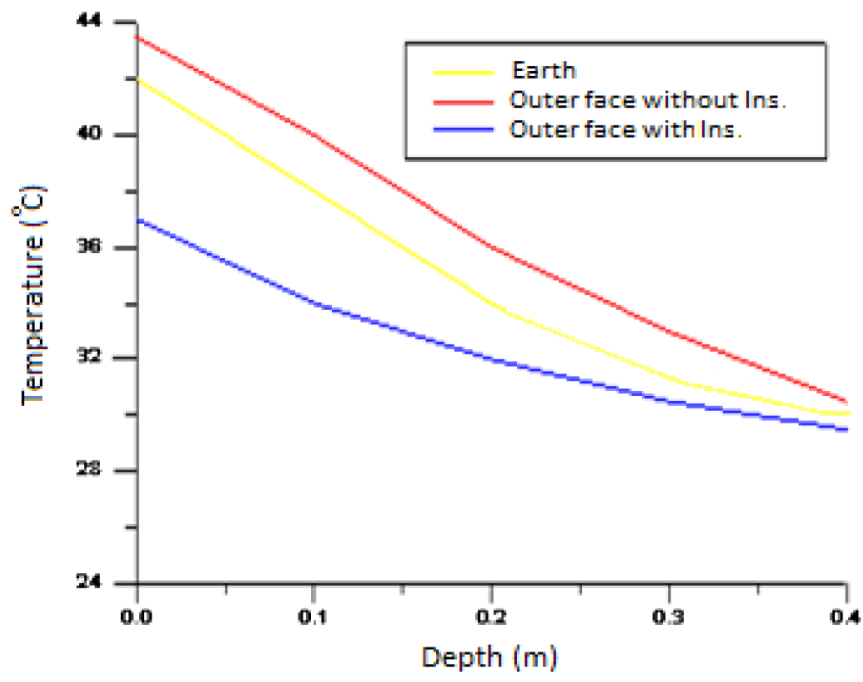

Fig. 7. Effect of insulation on the foundation (06 August - 10 August).

Then, the energy saving is given by:

$$
\begin{aligned}
& \text { Energy saving } \\
& =\frac{\text { Load for traditional model }- \text { Load for efficient model. }}{\text { Load for traditional model }}
\end{aligned}
$$

In the current study, an energy saving in the cooling load up to $70 \%$ can be recorded due to the efficient insulation as well as the passive techniques used.

\section{Conclusions}

The use of efficient insulation in hot dry areas is very urgent to reduce the energy consumption which has a direct impact related to economic and environmental issues. This study aims to evaluate the impact of efficient insulation in conjugate with some alternative solutions on the thermal performance of the building. The study introduces many solutions for passive design of the building in extreme hot climate, such as insulated foundation, double glazing, avoiding thermal bridges, air-tightness, underground ventilation system as well as canopy shading. The results of the present experimental work have shown a reduction in the indoor temperature of efficient model by $8^{\circ} \mathrm{C}$ comparing to that of traditional one, as well as stability in the variation of internal surface temperature by an average of $4^{\circ} \mathrm{C}$ comparing to a high fluctuation occurred in the traditional model. Furthermore, results show that the combined effect of both efficient insulated roof and canopy shading reduces the temperature of internal surface temperature of the roof by $12{ }^{\circ} \mathrm{C}$.

\section{References}

1. G.K. Abdulsada, T.W. Mohammed Salih, Experimental study to evaluate the performance of Iraqi passive house in summer season, J. Energy Power Eng. 9 (2015)

2. M. Yaohui, Z. Dezhi, C. Lin, W. Zheng, Y. Yan, L. Shuang, Analytical study on thermal stress of autoclaved aerated concrete shear walls, Roman. J. Mater. 48, 1620-167 (2018)

3. Ecovolve, Principles of thermal insulation: heat transfer via conduction, convection and radiation (2007), http://beo dom.com 
4. M. Al-Homoud, The effectiveness of thermal insulation in different types of buildings in hot climates, J. Therm. Env. Build. Sci. 27, 3 (2004)

5. A. Almusaed, K. Asaad, A. Almusaed, Towards a zero energy house strategy fitting for south Iraq climate, in Proceedings of PLEA2008: 25th Conference on Passive and Low Energy Architecture, Dublin, Oct. 22-24 (2008)

6. ISOVER, The ISOVER Multi Comfort House (2008), www. isover.net

7. S. Pongsuwan, The miracle of insulation in hot-humid climate building, Int. J. Renew. Energy 4, 1 (2009)

8. A. Kalif, A. Ismael, N. Hussein, Comparison of the thermal behavior for natural and industrial packaging materials on the cooling load in Baghdad, J. Babylon Univ. 21, 1450-1463 (2013)

9. ASHRAE, Chapter 27: Residential Cooling and Heating Load Calculations, ASHRAE Handbook SI (1997)

10. G.K. Abdulsada, T.W. Mohammed, Experimental and theoretical study for the performance of new local thermal insulation in Iraqi building, in Renewable Energy in the Service of Mankind (Springer, 2015), Chap. 44, Vol. I

11. S. Bekkouche, T. Benouaz, R. Kaoulal, M. Hamdani, M. Cherier, Improvement of thermo-aeraulic comfort with integrated solar wall system under Saharan climate, Renew. Energy Environ. Sustain. 1, 9 (2016)

12. M. Aboulnaga, M. Moustafa, Sustainability of higher educational buildings, Renew. Energy Environ. Sustain. 1, $28(2016)$
13. M. Ouakarrouch, N. Laaroussi, M. Garoum, Thermal characterization of a new biocomposite building material based on plaster and waste chicken feathers, Renew. Energy Environ. Sustain. 5, 2 (2020)

14. X. Liu, X. Chen, M. Shahrestani, Optimization of insulation thickness of external walls of residential buildings in hot summer and cold winter zone of China, Sustainability 12, $1574(2020)$

15. M. Alwetaishi, O. Benjeddou, A. Balabel, A. Alzaed, Can underground buildings be beneficial in hot regions? An investigation of field measurements in on-site built underground construction, Buildings 11, 341 (2021)

16. A.P. Melo, R. Lamberts, R.D. Versage, Y. Zhang, Is thermal insulation always beneficial in hot climate? in Proceedings of BS2015: 14th Conference of International Building Performance Simulation Association, India, Dec. 7-9, 2015

17. R. Divsalar, Building Problems in Hot Climates, MSc Thesis, Eastern Mediterranean University, North Cyprus (2010)

18. A. Moreno-Rangel, Passivhaus, Encyclopedia 1, 20-29 (2021)

19. B. Ford, R. Schiano-Phan, D. Zhongcheng, The Passivhaus Standard in European Warm Climates: Design Guidelines for Comfortable Low Energy Homes, School of the Built Environment, University of Nottingham (2007)

20. L. White, Passive Building in Hot and Humid Climates, in Proceeding of the 9th Annual North American Passive House Conference, USA (2014)

Cite this article as: Ghanim Kadhem Abdulsada, Tawfeeq Wasmi Mohammed Salih, The impact of efficient insulation on thermal performance of building elements in hot arid region, Renew. Energy Environ. Sustain. 7, 2 (2022) 